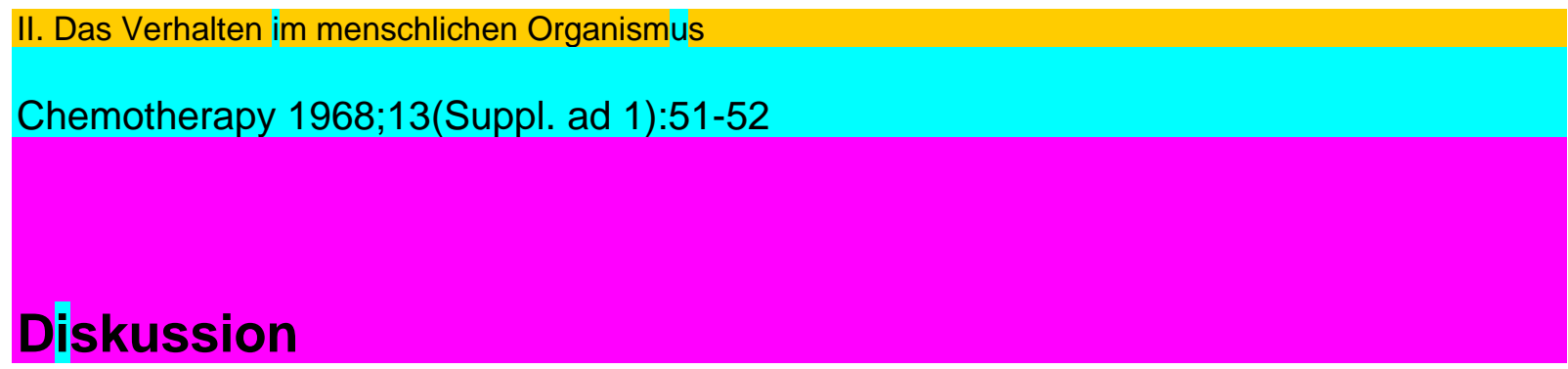

\title{
- Discussion
}

Dr. F. W. Reutter: Es war uns möglich, dank der Hilfe von Herrn Dr. Schweizer, bei 23

Patienten, welche einer Cholezystektomie unterworfen wurden, Bestimmun-gen von Vibramycin sowohl im Serum wie in der Galle vornehmen zu können. Was die Dosierung betrifft, so wurde ungefähr 28 Stunden vor Gewinnung der Proben $200 \mathrm{mg}$ und im Durchschnitt ungefähr 4 Stunden vor der Entnahme $100 \mathrm{mg}$ Vibramycin verabreicht. Bei einer Serumkonzentration von durchschnittlich 4,1 war die Konzentration von Vibramycin in der Gallenblase 29,8, also das Verhältnis Galle/Serum ungefähr 7, und somit sehr nahe den von Herrn Dr. Fabre erreichten Werten. In der aus dem Ductus choledochus gewonnenen Galle ist die Konzentration nicht so hoch und das Verhältnis ist dementsprechend nur ungefähr 3. Es zeigt sich aber doch, dass die Elimination von Vibramycin zu einem wesentlichen Teil durch die Gallenwege erfolgt und die Konzentration dort ganz bedeutend höher als im Serum ist.

Vibramycin-Konzentration in Serum und Galle

Anzahl Fälle durchschnittliche Vibramycin-Konzentration $\mu \mathrm{g} / \mathrm{ml}$

Serum Galle Galle

Gallenblase D. Choledochus Serum

$23 \quad 4,1 \quad 29,8 \quad 7,3$

$8 \quad 4,1 \quad 13,0 \quad 3,1$

Dr. A. Schläpfer: A la clinique pédiatrique de $\Gamma$ Université de Geneve, en collaboration avec $\Gamma$ lnstitut de Microbiologie Médicale, nous avons étudié les concentrations sériques de la Vibramycine chez 6 enfants dont $\Gamma$ âge variait de 10 à 14 ans. Les enfants ont reçu la

Vibramycine, sous forme de sirop, à raison de $4 \mathrm{mg} / \mathrm{kg}$ de poids le premier jour et de $2 \mathrm{mg} / \mathrm{kg}$ de poids le deuxième, le troisième et le quatrième jour. Nous avons fait 3 prélèvements sanguins, 2 $\mathrm{h}, 12 \mathrm{~h}$ et $24 \mathrm{~h}$ après chaque prise.

Les résultats d'ensemble sont relates dans la figure 1, où les traits pointillés donnent les résultats individuels de chaque enfant et le trait plein la moyenne. Deux heures après $\Gamma$ administration, nous obtenons des taux sanguins compris entre 3 et $5 \mu \mathrm{g} / \mathrm{ml}$ avec une moyenne de $4,22.24 \mathrm{~h}$ après, ces taux sériques sont encore très voisins de $1 \mu \mathrm{g} / \mathrm{ml}$ à $\Gamma$ exception d'un enfant qui se trouve toujours au-dessous de ces valeurs et dont les taux sériques sont situés vers $0,45 \mu$ glaú. II s'agit là d'un enfant dystrophique de $14 \mathrm{ans}$, avec un poids corporel de $20 \mathrm{~kg}$, et on ne peut done trop insister sur les valeurs obtenues dans ce cas.

52

Diskussion - Discussion

$02 \quad 12$

*4mg/kg Fig. 1

$\begin{array}{llll}2426 & 36 & 48 & 60\end{array}$

*2mgkg $\quad * 2 \mathrm{mg} / \mathrm{kg}$

$120 \mathrm{~h}$ 
\200mg $4 \mathrm{mg} / \mathrm{kg}$

* $100 \mathrm{mg} 2 \mathrm{mg} / \mathrm{kg}$

Fig. 2

D. Dans la figure 2

nous avons compare les resultats que nous avons obtenus chez $\Gamma$ enfant après administration de sirop avec les resultats obtenus par Dr. J. Fabre chez Tadulte après administration de capsules.

On constate dans $\Gamma$ ensemble une bonne concordance des resultats

les taux sanguins chez $\Gamma$ enfant montant au debut probablement un peu plus rapidement et ayant une tendance à s'abaisser également plus rapidement. La demi-vie pratique que nous avons calculée est aux alentours de $19 \mathrm{~h}$. 